\title{
Low rate of TP53 germline mutations in breast cancer/sarcoma families not fulfilling classical criteria for Li-Fraumeni syndrome
}

\author{
D G R Evans, J M Birch, M Thorneycroft, G McGown, F Lalloo, J M Varley
}

J Med Genet 2002;39:941-944

B reast cancer and sarcoma are key components of Li-Fraumeni syndrome (LFS). ${ }^{1-6}$ Sarcoma, particularly childhood osteosarcoma or rhabdomyosarcoma in addition to childhood adrenocortical carcinoma (ACC), is the strongest predictor of the presence of a TP53 mutation. ${ }^{78}$ However, while up to $80 \%$ of unselected series of ACC have TP53 germline mutations, ${ }^{8}$ only $3-10 \%$ of unselected sarcomas have been found to have such mutations. ${ }^{9-11}$ At least half of these would have been predicted on the basis of family history and many of the rest could have arisen de novo. ${ }^{12}$ While breast cancer is common in LFS and the penetrance of TP53 germline mutations in women for breast cancer may be as high as $56 \%$ by the age of 45 years ( $80 \%$ of female cancer incidence aged $16-45$ years), ${ }^{13}{ }^{14}$ it is also common in the general population with nearly $2 \%$ of women now developing breast cancer by the age of 50 in the general population in the western world. ${ }^{15}{ }^{16} \mathrm{In}$ contrast to sarcoma and ACC, there are other more common inherited syndromes to account for familial aggregation of breast cancer $(B R C A 1 / 2)$. As a major referral centre for research testing for TP53, we have become aware that the possibility of TP53 mutations is often raised fairly strongly in the context of even a single case of sarcoma in addition to breast cancer. In order to assess the likelihood of TP53 germline mutations in this population, we have assessed the outcome of such testing in families containing a single (but no more) sarcoma and at least one breast cancer where the family as a whole does not fulfil LFS criteria.

\section{MATERIAL AND METHODS}

Over the last 20 years our group has ascertained families with a history of early onset tumours in addition to sarcoma. ${ }^{4-6}{ }^{17} \mathrm{In}$ the last 10 years we have also received samples from families ascertained at other genetics and oncology centres in the UK. We have retrospectively analysed the outcome of TP53 germline mutation testing in families with a single proven sarcoma where that person or a first degree relative developed early onset ( $<60$ years) breast cancer, but the family as a whole did not fulfil criteria for classical LFS (table 1). Twentyone such families were identified (table 2) in addition to 30 families which we had tested that fulfilled classical criteria. Twenty-five families which fulfilled criteria for Li-Fraumenilike (LFL, table 1) were tested including seven from the 21 identified in the current study. ${ }^{17}$ The families in this study fulfilling LFL criteria were compared with the 18 LFL families not including a single sarcoma or breast cancer occurrence.

Mutation detection was carried out as described previously. ${ }^{7}$ All exons (coding and non-coding), all splice junctions, the promoter, and the 3' untranslated region were analysed by direct sequencing. Any sequence variants were confirmed by sequencing the complementary strand. Wherever possible, multiple affected subjects from the families were analysed to verify that any putative mutation segregated with the disease. All these studies were carried out with approval of relevant local ethics committees.

\section{Key points}

- Mutations in the TP53 gene account for the great majority (circa $70 \%$ ) of families fulfilling classical criteria for Li-Fraumeni syndrome and a significant portion of families falling just short of these criteria.

- We have undertaken a study to determine the contribution of TP53 germline mutations to families containing breast cancer and a single proven sarcoma, which fall short of classical criteria for LFS.

- Blood samples from a sarcoma patient or a first degree relative with breast cancer were analysed for mutations in TP53 by direct sequencing of all exons, the promoter, and 3 ' untranslated region. Only one mutation was identified in $21(5 \%)$ eligible families compared to $23 / 30(77 \%)$ of families fulfilling classical Li-Fraumeni syndrome criteria.

- These results suggest that breast cancer on its own (in addition to a sarcoma) may not be a particularly strong marker for TP53 mutations and that this should be taken into account in genetic counselling. The addition of even early onset breast cancer to a sarcoma may not be sufficient to justify TP53 mutation testing.

Table 1 Diagnostic criteria for Li-Fraumeni syndrome and Li-Fraumeni-like syndrome

\begin{tabular}{ll}
\hline Li-Fraumeni syndrome $^{3}$ & Li-Fraumeni like syndrome $^{17}$ \\
\hline $\begin{array}{l}\text { Proband }<45 \text { years with a } \\
\text { sarcoma }\end{array}$ & $\begin{array}{l}\text { Proband with any childhood } \\
\text { tumour, or sarcoma, brain tumour, } \\
\text { or adrenocortical tumour }<45 \\
\text { years }\end{array}$ \\
$\begin{array}{ll}\text { Plus } 1 \text { st degree relative }<45 \text { years } \\
\text { with any cancer }\end{array}$ & $\begin{array}{l}\text { Plus } 1 \text { st or 2nd degree relative in } \\
\text { the same lineage with typical LFS } \\
\text { tumour at any age or any cancer } \\
<45 \text { years }\end{array}$ \\
$\begin{array}{ll}\text { Plus additional 1st or 2nd degree } \\
\text { relative in the same lineage aged } \\
<45 \text { years with any cancer or a } \\
\text { sarcoma at any age }\end{array}$ & $\begin{array}{l}\text { relative in the same lineage with } \\
\text { any cancer }<60 \text { years }\end{array}$ \\
\hline
\end{tabular}

\section{RESULTS}

Only one mutation was identified in the 21 breast/sarcoma families studied. This family (family 2252, table 2) only failed to meet LFS criteria as the sarcoma was diagnosed four years after the qualifying date ( 49 rather than $<45$ years). There is also a suggestion of a further sarcoma in the mother of the tested subject who died from an intra-abdominal malignancy aged 23 years that has not been possible to confirm. The 
Table 2 Cancers in eligible families

\begin{tabular}{|c|c|c|c|c|c|c|}
\hline Family & LFL & Breast cancer & $\begin{array}{l}\text { Osteosarcoma } \\
\text { (age) }\end{array}$ & Other sarcoma & $\begin{array}{l}\text { Other LFS spectrum } \\
\text { cancers }\end{array}$ & Other cancers \\
\hline 729 & Yes & $42^{*}, 52$ & Femur 9 & & & \\
\hline 2063 & Yes & $47 / 49 *, 58$ & Femur 13 & & & \\
\hline A & No & $51^{*} \dagger$ & Femur 15 & Ovary $59 * \dagger$ & & \\
\hline B & No & $42 * \dagger, 32$ & & 48 & & Cervix $35^{*} \dagger$ \\
\hline C & No & $34^{*} \dagger$ & & Abdomen $66^{*} \dagger$ & & $\operatorname{BCC} 67^{*} \dagger$ \\
\hline D & No & $55^{*}$ & & Fibrosarcoma 67 & & Colon 42, RCC 39 \\
\hline $\mathrm{E}$ & No & $55^{*} \dagger$ & Femur 18 & & & Melanoma $31 * \dagger$ \\
\hline $\mathrm{F}$ & No & $35^{*} \dagger$ & Radius $40^{*} \dagger$ & & & \\
\hline G & No & $29^{*}, 40 \dagger$ & & Abdomen 45† & & \\
\hline $\mathrm{H}$ & No & 31 * & & Uterus 62 & & \\
\hline I & No & $38^{*} \dagger$ & Femur $18 * \dagger$ & & & \\
\hline J & No & $42^{*}, 62$ & Humerus 2 & & & \\
\hline K & No & $45 / 54^{*} \dagger, 73$ & & Synovial 27 & & Oesophagus $57^{*} \dagger$ \\
\hline $\mathrm{L}$ & No & $30,44^{*} \dagger$ & & Pelvis $55^{*} \dagger$ & & \\
\hline$M$ & No & $39 * \dagger$ & & Fibrosarcoma $33^{*} \dagger$ & & \\
\hline $\mathrm{N}$ & No & $37^{*} \dagger$ & Femur $15^{*} \dagger$ & & & \\
\hline $2252 \ddagger$ & Yes & $25,26 / 40^{*} \dagger$ & & Leiomyosarcoma buttock $49 * \dagger$ & $\begin{array}{l}\text { Glioblastoma 15, PNET } \\
10,\end{array}$ & Abdominal malignancy 23 \\
\hline 338 & Yes & $36 / 44^{*} \dagger$ & & Chondrosarcoma $35^{*} \dagger$ & PNET 7 & \\
\hline 80 & Yes & $35^{*} \dagger, 29,60$ & & Liposarcoma 30* & & Ovary 51 , rectal 44 \\
\hline 328 & Yes & 45 & 16 * & & Glioma 56 & \\
\hline 1799 & Yes & $37^{*} \dagger$ & & Soft tissue $37^{*} \dagger$ & & Stomach 48,42 \\
\hline
\end{tabular}

Cancers are those in the sarcoma patient and breast cancer patient and in their first degree relatives.

* Indicates subject tested. Individual multiple primaries in a single person in a family leg family 2252 contains a female with bilateral breast cancer aged 26 and 40 and a leiomyosarcoma aged 49 years); $45 / 50$ indicates bilateral disease. ‡lndicates only family with proven TP53 germline mutation. Numbered families are those classified as LFL, which are also previously published.

mutation, a 2 base pair deletion at codon 191 leading to a frameshift and a stop codon, has previously been reported by $\mathrm{us}^{18}$ as have negative reports for the six other LFL families (table 2) with a case of a sarcoma and breast cancer $(80,328$, $338,348,729,2063) .^{7}$ Family 348 was previously published as a LFL family but the breast cancer at 73 has been subsequently found to be DCIS. None of the other families has been reported previously.

We have now extended our survey of classical LFS families to 30 and detected mutations in 23 (77\%). In LFL families, $10 / 25(40 \%)$ had mutations. Excluding the seven LFL families in the current survey, mutations were detected in 9/18 (50\%) compared to only $1 / 7$ (14\%) in the breast sarcoma set.

\section{DISCUSSION}

We have been rather surprised by the low rate of TP53 mutations detected in families fulfilling our breast/sarcoma criteria. It is possible that we may not always have been able to test the most appropriate person (the sarcoma case) and that testing their affected mother may have failed to show a mutation that had occurred after conception (mosaic) but nonetheless was passed down to the affected offspring. ${ }^{19}$ However, this mechanism could only account for families A, L, and 338 as all other tested subjects in multi-case families were in the second or third generation of affected subjects (unless the first generation was a phenocopy). Nonetheless the four isolated breast/sarcoma double primaries (families C, F, I, and M) could also have been mosaic for a TP53 mutation. It is unlikely that mosaicism would account for a significant miss rate in our study, as even in NF2 the rate of mosaicism in de novo cases is no higher than $20 \% .{ }^{20}$ It is also possible that mutations in these families could have been missed owing to the sensitivity of the mutation techniques. However, given that mutations were detected in $77 \%$ of classical families, it is unlikely that more than one mutation would have escaped detection. It is possible that there may be another gene that accounts for Li-Fraumeni syndrome, which is more common in families with a predominance of breast cancer. However, recent evidence has shown that the CHK2 gene may not be a real Li-Fraumeni syndrome gene. ${ }^{21}$ While an original report of one of our families with a CHK2 mutation appeared to herald this as the second LFS gene, ${ }^{22}$ it now appears that the mutation is a modifier of risk for genes other than BRCA1 and BRCA2 rather than a high risk allele in its own right. ${ }^{21}$

Although breast cancer is a very common feature in LFS and LFL families, it is probable that it is the presence of other characteristic tumours in addition to sarcoma that are the key predictors. It is of note that family 2252 (the only mutation positive LFL family) is the only one to contain at least two typical LFS tumours (PNET 10 years, glioblastoma 15 years) and that only two other families, 338 and 328, contained a single typical tumour with only one of these being childhood at onset. Three groups have now collectively analysed more than 800 unselected breast cancer patients for TP53 germline mutations. ${ }^{23-25}$ Among these cases, germline TP53 mutations were detected in only two $(0.25 \%)$ so such mutations are clearly rare among apparently sporadic breast cancers. Two of these reports ${ }^{23} 25$ along with a further report $\mathrm{t}^{26}$ have analysed series of breast cancers in patients selected because of family history of breast cancer or early onset (under 40 years of age) disease. A total of 274 such cases have been analysed and among these four patients with germline TP53 mutations were detected (1.5\%). We have recently analysed an even younger set of unselected patients aged 30 years or less and identified 4/99 (4\%) with germline TP53 mutations. ${ }^{27}$ Two of these were predicted on the basis of a family history conforming to LFS or LFL and a further sporadic patient was shown to have a de novo change. It is clear, therefore, that germline TP53 mutations account for only a small number even among selected breast cancer cases. Interestingly one of the LFL families in the $<31$ years set had a BRCA2 mutation. ${ }^{27}$

It is conceivable therefore that some of the families in table 2 could be caused by mutations in BRCA1 or BRCA2. Half of them contain multiple cases of breast cancer and if sarcoma was a rare feature of $B R C A I / 2$ mutations it might not yet have been identified as such. Indeed, we have recently found an increased risk of sarcoma in the relatives of incident breast cancer cases. ${ }^{28}$ Ignoring the sarcoma patients in each family, several of these might be expected to have mutations in BRCAI/2.

Perhaps the most surprising group of patients not to be identified with a TP53 mutation were those with breastsarcoma double primaries, in particular in family I where a 
woman developed breast cancer at 38 years following an osteosarcoma at 18 years. However, Malkin et al ${ }^{29}$ reported TP53 germline mutations in only four of 59 children and young adults with second primary cancers and, indeed, this was later corrected to three out of the 59 (5\%).

Chompret et al ${ }^{30}$ have attempted to devise criteria to assess the sensitivity and positive predictive value of TP53 germline mutation testing. Including their previous study of childhood tumours, they added a series of 116 breast cancers aged less than 36 years at diagnosis out of a series of 275 eligible cases. They identified three mutations in this series with two occurring in the context of classical LFS. One of these patients appeared to represent an isolated case of breast cancer at 31 years, but no information on testing of relatives was mentioned and this may have been de novo. Using the stringent criteria in this analysis, we have identified 5/21 families with a incident breast cancer $<36$ years in which a first or second degree relative developed an unquestioned LFS tumour (sarcoma, brain, breast cancer, ACC). Both the cases identified from the 116 incident breast cancer series had mutations if breast cancer was excluded as the cancer in the relative, but $0 / 21$ had mutations if breast cancer was taken as the only relevant cancer. In contrast, we have identified only $1 / 5(20 \%)$ of those fulfilling the stringent criteria in Chompret et $a^{30}$ (all our families fulfilled the breast cancer exclusion criteria as sarcoma was the main ascertainment criterion for our study). If we include the breast-sarcoma double primary cases (the sarcoma counted as a relative), this drops to $1 / 8(12.5 \%)$ where the breast cancer was $<36$ years. Given that both the families in the French breast cancer series fulfilled LFS criteria, use of even the stringent criteria from this study is questionable. It would appear that LFS and LFL criteria have a much higher positive predictive value and specificity than the French stringent criteria. However, all these criteria will fall down on sensitivity given the possibility of de novo $m$ utation

In summary, our report has pointed to a low detection rate for TP53 mutations in breast/sarcoma families not conforming to LFS. Indeed, it is questionable whether such testing should be initiated if the history does not even fulfil LFL criteria (LFL criteria excluding breast cancer as the main other tumour has a high positive predictive value, $50 \%$ ). Certainly the $5 \%(1 / 21)$ mutation rate in the series as a whole is lower than the $10 \%$ guideline suggested by ASCO. Given the particularly difficult issues of genetic counselling and the low uptake of presymptomatic testing in TP53 families, ${ }^{31}{ }^{32}$ it is debatable how strongly the possibility of a TP53 mutation should be raised, particularly in older onset breast/sarcoma families. While it is possible that such aggregations may be the result of other, as yet unidentified genes, the possibility that many of these could have occurred by chance should not be dismissed.

\section{Authors' affiliations}

D G R Evans, F Lalloo, Academic Unit of Medical Genetics and Regional Genetics Service, St Mary's Hospital, Manchester M13 OJH, UK J M Birch, CRC Paediatric and Familial Cancer Research Group, Royal Manchester Hospital, Pendlebury, Manchester, UK

J M Varley, M Thorneycroft, G McGown, CRC Cancer Genetics Laboratory, Paterson Institute for Cancer Research, Christie Hospital, Manchester M20 9BX, UK

Correspondence to: Dr D G R Evans, Academic Unit of Medical Genetics and Regional Genetics Service, St Mary's Hospital, Hathersage Road, Manchester M13 OJH, UK; Gareth.Evans@cmmc.nhs.uk

\section{REFERENCES}

1 Li FP, Fraumeni JF Jr. Soft-tissue sarcomas, breast cancer, and other neoplasms. A familial syndrome? Ann Intern Med 1969;71:747-52.

2 Li FP, Fraumeni JF Jr. Prospective study of a family cancer syndrome. JAMA 1982;247:2692-4.
3 Li FP, Fraumeni JF Jr, Mulvihill JJ, Blattner WA, Dreyfus MG, Tucker MA, Miller RW. A cancer family syndrome in twenty-four kindreds. Cancer Res 1988;48:5358-62

4 Birch JM, Hartley AL, Marsden HB, Harris M, Swindell R. Excess risk of breast cancer in the mothers of children with soft tissue sarcomas. $\mathrm{Br} J$ Cancer 1984:49:325-31.

5 Birch JM, Hartley AL, Blair V, Kelsey AH, Harris M, Teare MD, Morris-Jones $\mathrm{PH}$. Cancer in the families of children with soft tissue sarcoma. Cancer 1990;66:2239-48

6 Birch JM, Hartley AL, Blair V, Kelsey AM, Harris M, Teare MD, Jones $\mathrm{PH}$. Identification of factors associated with high breast cancer risk in the mothers of children with soft tissue sarcoma. J Clin Oncol 1990;8:583-90.

7 Varley JM, McGown G, Thorncroft M, Santibanez-Koref MF, Kelsey AM, Tricker KJ, Evans DGR, Birch JM. Germ-line mutations of TP53 in Li-Fraumeni families: an extended study of 39 families. Cancer Res 1997;57;3245-52.

8 Varley JM, McGown G, Thorncroft M, Evans DGR, Kelsey AM, Birch JM. Are there low-penetrance TP53 alleles? Evidence from childhood adrenocortical tumors. Am J Hum Genet 1999;65:995-1006.

9 Mclntyre JF, Smith-Sorensen B, Friend SH, Kassell J, Borresen AL, Yan YX, Russo C, Sato J, Barbier N, Miser J, Malkin D, Gebhardt MC. Germline mutations of the p53 tumor suppressor gene in children with osteosarcoma. J Clin Oncol 1994;12:925-30.

10 Toguchida J, Yamaguchi T, Dayton SH, Beauchamp RL, Herrera GE, Ishizaki K, Yamamuro T, Meyers PA, Little JB, Sasaki MS, Weichselbaum RR, Yandell DW. Prevalence and spectrum of germline mutations of the p53 gene among patients with sarcoma. N Engl J Med 1992:326:1301-8.

11 Diller L, Sexsmith E, Gottlieb A, Li FP, Malkin D. Germline p53 mutations are frequently detected in young children with rhabdomyosarcoma. J Clin Invest 1995;95:1606-11

12 Ayan I, Luca JW, Jaffe N. De novo germline mutations of the p53 gene in young children with sarcomas. Oncol Rep 1997;4:679-83.

13 Birch JM, Alston RD, McNally RJQ, Evans DGR, Kelsey AM, Harris M, Eden OB, Varley JM. Relative frequency and morphology of cancers in carriers of germline TP53 mutations. Oncogene 2001;20:4621-8.

14 Chompret A, Brugières L, Ronsin M, Gardes M, Dessarps-Freichey $F$, Abel A, Hua D, Ligot L, Dondon MG, Bressac-de Paillerets B, Frebourg T, Lemerle J, Bonaiti-Pellie C, Feunteun J. p53 germline mutations in childhood cancers and cancer risk for carrier individuals. Br J Cancer 2000;82:1932-7

15 Office for National Statistics. Annual report on cancer registration statistics (MB 1/29), England, 1998

16 Miller BA, Fever DJ, Hankey BF. Recent incidence trends for breast cancer in women and relevance of early detection: an update. $C A$ Cancer J Clin 1993:43:27-41.

17 Birch JM, Hartley AL, Tricker KJ, Tricker KJ, Prosser J, Kelsey AM, Harris $M$, Morris-Jones PH, Crowther D, Craft AW, Eden OB, Evans DGR, Thompson E, Mann J, Martin J. Prevalence and diversity of constitutional mutations in the p53 gene among 21 Li-Fraumeni families. Cancer Res 1994:54:1298-304.

18 Varley JM, Thorncroft M, McGown G, Tricker K, Birch JM, Evans DGR. A novel deletion within exon 6 of TP53 in a family with Li Fraumeni-like syndrome, and $\mathrm{LOH}$ in a benign lesion from a mutation carrier. Cancer Genet Cytogenet 1996;90:14-16.

19 Kovar H, Auinger A, Jug G, Müller T, Pillwein K. p53 mosaicism with an exon 8 germline mutation in the founder of a cancer-prone pedigree. Oncogene 1992;7:2169-73.

20 Evans DGR, Truman L, Wallace A, Strachan, T. Mosaicism in classical NF2: a common mechanism for sporadic disease in tumour prone syndromes? Am J Hum Genet 1998;63:727-36.

21 Meijers-Heijboer $\mathbf{H}$, van den Ouweland A, Klijn J, Wasielewski M, de Snoo A, Oldenburg R, Hollestelle A, Houben M, Crepin E, van Veghel-Plandsoen M, Elstrodt F, van Duijn C, Bartels C, Meijers C Schutte M, McGuffog L, Thompson D, Easton DF, Sodha N, Seal S, Barfoot R, Mangion J, Chang-Claude J, Eccles D, Eeles R, Evans DG Houlston R, Murday V, Narod S, Peretz T, Peto J, Phelan C, Zhang HX, Szabo C, Devilee P, Goldgar D, Futreal PA, Nathanson KL, Weber BL, Rahman N, Stratton MR.. Low penetrance breast cancer susceptibility due to CHK2 1 100delC in non-carriers of BRCA 1 or BRCA2 mutations. Nat to CHK2 2002;31:55-9.

22 Bell DW, Varley JM, Szydlo TE, Kang DH, Wahrer DC, Shannon KE, Lubratovich M, Verselis SJ, Isselbacher KJ, Fraumeni JF, Birch JM, Li FP Garber JA, Haber DA. Heterozygous germ line hCHK2 mutations in Li-Fraumeni syndrome. Science 1999;286:2528-31.

23 Børresen AL, Andersen TI, Garber J. Screening for germ line TP53 mutations in breast cancer patients. Cancer Res 1992;52:3234-6.

24 Prosser J, Porter D, Coles C, Condie A, Thompson AM, Chetty U, Steel $\mathrm{CM}$, Evans HJ. Constitutional p53 mutation in a non-Li-Fraumeni cance family. Br J Cancer 1992:65:527-8.

25 Sidransky D, Tokino T, Helzlsouer K, Zehnbauer B, Rausch G, Shelton B Prestigiacoma L, Vogelstein B, Davidson N. Inherited p53 gene mutations in breast cancer. Cancer Res 1992;52:2984-6.

26 Rapakko K, Allinen M, Syrjakoski, K, Vahteristo P, Huusko P, Vahakangas K, Eerola $\mathrm{H}$, Kainu T, Kallioniemi OP, Nevanlinna $\mathrm{H}_{\text {, }}$ Winqvist R. Germline TP53 alterations in Finnish breast cancer families are rare and occur at conserved mutation-prone sites. $\mathrm{Br} J$ Cancer 2001;84:116-19.

27 Lalloo F, Varley J, Ellis D, O'Dair L, Pharoah P, Evans DGR, and the Early Onset Breast Cancer Study Group. Family history is predictive of pathogenic mutations in BRCA1, BRCA2 and TP53 with high penetrance in a population based study of very early onset breast cancer. Lancet (in press). 
28 Bennett KE, Howell A, Evans DGR, Birch JM. A follow-up study of breast and other cancers in families of an unselected series of breast cancer patients. Br J Cancer 2002;86:718-22.

29 Malkin D, Friend SH, Li FP, Strong LC. Germ-line mutations of the p53 tumor-suppressor gene in children and young adults with second malignant neoplasms. N Engl J Med 1997;336:734.
30 Chompret A, Abel A, Stoppa-Lyonnet D, Brugieres L, Pages S, Feunten J, Bonaite-Pellie $C$. Sensitivity and predictive value of criteria for $\mathrm{p} 53$ Bonaite-Pellie C. Sensitivity and predictive value of criteria

germline mutation screening. J Med Genet 2001;38:43-7. 1 Evans DGR, Maher ER, Macleod R, Davies DR, Craufurd D. Uptake of

32 Schneider KA, Patenaude AF, Garber JE. Testing for cancer genes: decisions, decisions. Nat Med 1994:1:302-3.

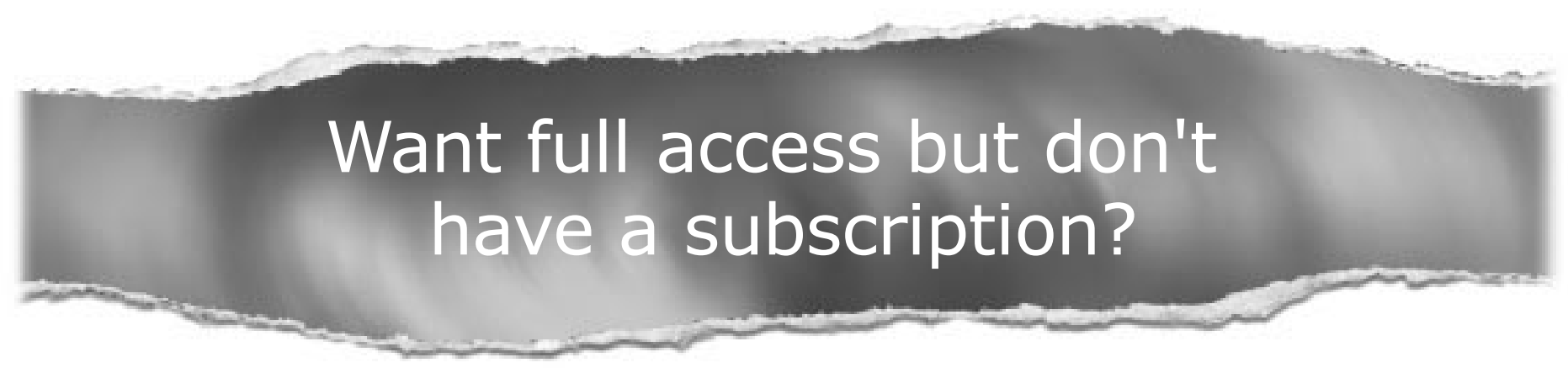

\section{Pay per access}

For just US $\$ 25$ you can have instant access to the whole website for 30 days. During this time you will be able to access the full text for all issues (including supplements) available. You will also be able to download and print any relevant pdf files for personal use, and take advantage of all the special features Journal of Medical Genetics online has to offer.

\section{www.jmedgenet.com}

